\title{
Does education strengthen the life skills of adolescents?
}

\section{Secondary and higher education are windows of opportunity for boosting students' life skills}

Keywords: human capital development, life skills, noncognitive skills, secondary and tertiary education, measurement error

\section{ELEVATOR PITCH}

Life skills, sometimes referred to as noncognitive skills or personality traits (e.g. conscientiousness or locus of control-the belief to influence events and their outcomes), affect labor market productivity. Policy makers and academics are thus exploring whether such skills should be taught at the high school or college level. A small portfolio of recent studies shows encouraging evidence that education could strengthen life skills in adolescence. However, as no uniform approach exists on which life skills are most important and how to best measure them, many important questions must be answered before life skill development can become an integral part of school curricula.

\section{KEY FINDINGS}

\section{Pros}

( Adolescence offers a window of opportunity to teach life skills when the human brain is malleable.

- Recent studies show that life skills can be boosted in adolescence through education or education interventions.

( There is consistent evidence of a positive impact of education on extraversion and behavioral proxies of life skills.

๑ The estimated impact of education initiatives on life skills is modest, though it is comparable to the effect of early childhood programs.

๑ Cognitive behavioral therapy may be a promising tool for life skill development.

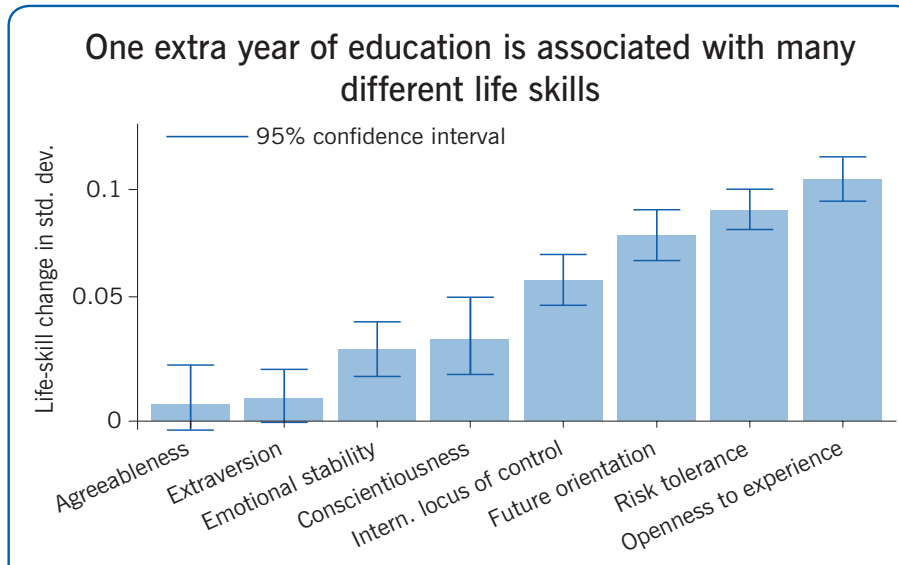

Source: Author's own calculations using HILDA data, 2005-2013. Online at: https://www.melbourneinstitute.com/hilda/

\section{Cons}

- General conclusions from the small evidence base are not possible because of the broad diversity in measuring skills and education.

- Studies that evaluate specific life skill interventions rely on invalidated behavioral proxies, and are thus less reliable.

- Some studies even report negative impacts of education on life skill development, raising concerns about correct measurements of skills.

- Empirical evidence on the (cost-)effectiveness of concrete interventions is scarce.

- The evidence base is too limited to effectively inform policymakers on the implementation of life skill development in school curricula.

\section{AUTHOR'S MAIN MESSAGE}

Although preliminary evidence suggests that some life skills can be strengthened in secondary education settings, the literature is still in its infancy. Many important questions remain unresolved. For instance, it is still unknown which life skills are malleable and thus most conducive for instruction in school curricula. Chicago's "Becoming a Man" program, which changes thinking patterns of at-risk youth in school through cognitive behavioral therapy, provides an example of how to craft cost-effective intervention measures; however, additional research is needed on similar programs and on reliable measurement tools to track skill development. 


\section{MOTIVATION}

Life skills, sometimes referred to as noncognitive skills, socio-emotional learning, character traits, or personality traits, are defined as: "skills not captured by assessments of cognitive ability and knowledge" [1]. Some life skills-conscientiousness, self-esteem, internal locus of control, or grit-have made headlines because they have the potential to improve individuals' labor market productivity.

Traditionally, life skill development is not included in education policy, but social scientists and policymakers are increasingly asking whether life skills can be strengthened, and, if so, at what stages of child development. Most findings come from early childhood and elementary school interventions, which show that high-quality programs can strengthen life skills in the long term. Because life skills appear more malleable than cognitive ability, some argue that these skills should be taught in schools-preferably before the age of five (see [2] for an overview).

An important question to consider is whether the education sector can play a role in strengthening life skills at later stages of child development. High schools and colleges might consider adding life skills to their curricula because the adolescent brain is particularly open to incentives and socio-emotional influences. Some governments are in the process of revising their high school curricula to introduce life skill development-for instance in the US (California), as well as in Canada (Ottawa-Carleton) and Australia (Victoria). Even though there is little research so far on how life skills can be taught and assessed objectively, a small portfolio of recent research findings suggest that including them in high school curricula may be an effective strategy to strengthen adolescents' life skills.

\section{DISCUSSION OF PROS AND CONS}

\section{Overview of findings}

Several recent studies have estimated the causal impact of schooling or interventions in secondary or tertiary education settings on life skill development. Figure 1 summarizes their results with the standardized treatment effects (standard deviation) plotted on the horizontal axis and with each study listed on the vertical axis. The treatments considered in each study differ widely, as can be seen from a summary presented in Figure 2. For instance, schooling is defined in a broad sense that encompasses years of schooling [3], university education [4], the learning intensity in high school [5], [6], class size [7], and teacher quality [8]. School programs and interventions that explicitly target life skills comprise US-based charter schools [1], [9], England's "XL Club program" [10], as well as Chicago's "Becoming a Man" program [11] and "OneGoal" program [2]. There are many more evaluated school programs aimed at strengthening life skills. However, studies of those programs assess their impacts solely on academic achievement.

Moreover, there is a large degree of diversity in the types of life skills being evaluated. Some studies use the big five personality traits, a widely accepted model to describe five broad dimensions of personality including openness to experience, conscientiousness, extraversion, agreeableness, and neuroticism [4], [5], [6], whereas others rely on a mix of measures such as self-esteem, internal locus of control [3], grit, self-control, or stand-ins of economic preferences [1], [9], [10], [11]. Some studies use certain behavioral proxies of life skills derived from administrative data such as absentee rates, in-class effort, or ontime graduation [2], [7], [8]. 
Figure 1. Life skill returns of schooling, education reforms, or school interventions
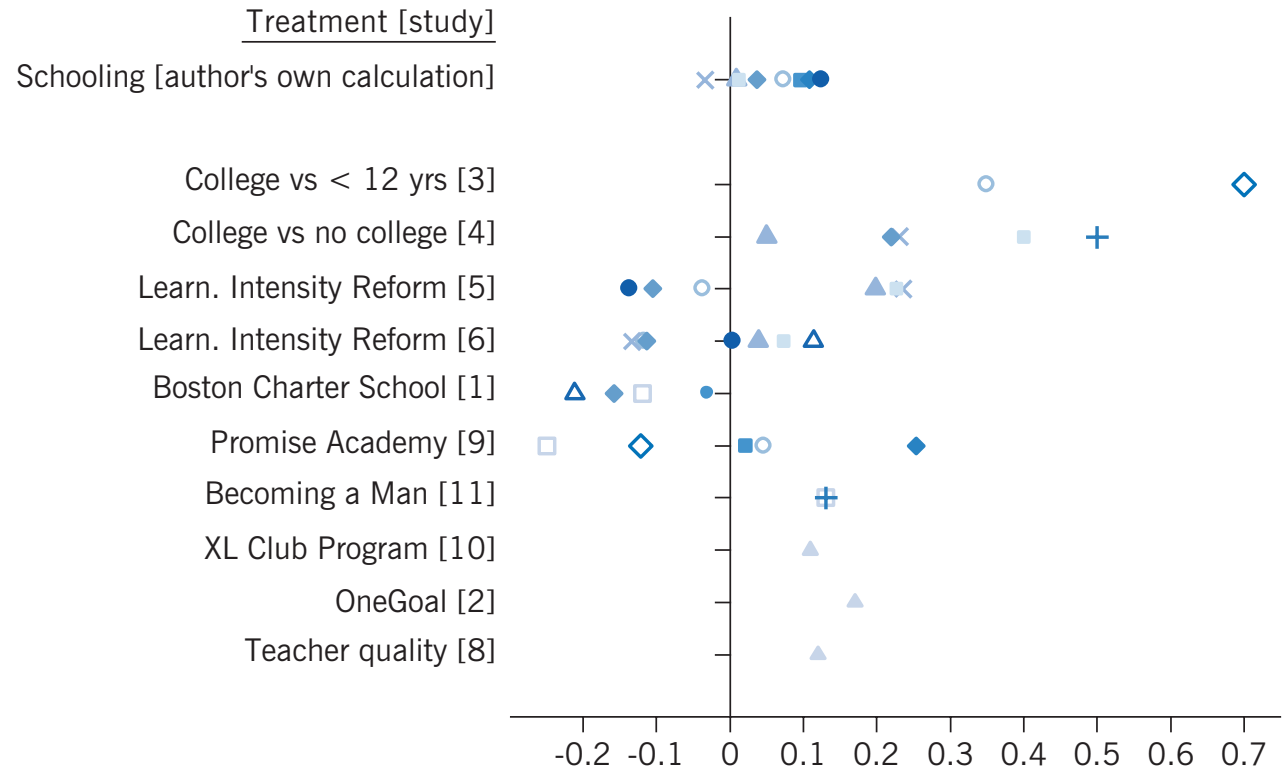

Treatment effect of education on life skills in std. dev.
$\triangle$ Agreeableness
$\triangle \quad$ Behavioral proxy
$\square \quad$ Grit
Conscientiousn.
+ Emot. health
- Growth minds.
- Openness
- Extraversion
- Future orientat.
$\diamond$ Self-esteem
- Risk tolerance

Note: Each row plots the treatment effects of interest from a separate study, followed by a short description of the type of treatment. The treatment effect is expressed in terms of standard deviation (std. dev.) away from the zero sample mean. Each geometric shape represents a specific life skill. The life skills studied are: big five personality traits, internal locus of control, self-esteem, grit, self-control, growth mindset, risk tolerance, future orientation, and behavioral proxies derived from administrative data.

Source: For full source details see: http://wol.iza.org/articles/does-education-strengthen-the-life-skills-of-adolescents

Calculations of the relationship between years of schooling and standard measures of life skills (i.e. big five, internal locus of control, risk tolerance, future orientation) using data from the Household, Income, and Labour Dynamics in Australia (HILDA) survey, demonstrate a significant link between education and almost all life skills. However, these associations do not mean necessarily that education causes life skill development; it may just be the case that individuals with higher levels of openness to experience or an internal locus of control may be more likely to seek higher levels of education. Alternatively, there may be unobserved factors that affect both education decisions and life skill development.

To judge whether higher levels of education cause life skill improvements requires the availability of some exogenous variation in (aspects of) education. As shown in Figure 2, the reviewed studies demonstrate a great degree of diversity in the methods and modeling assumptions used to identify causal effects. Studies that use nationally representative survey data-similar in design to HILDA-in combination with strong modeling assumptions usually find some significant positive effects of schooling [3], [5], [6] or university education [4]. Although they consistently find a significant effect on extraversion, a skill associated with sociability, there is conflicting evidence for some life skills, including conscientiousness or internal locus of control. In some cases, the effects are even negative, as with conscientiousness. On the other hand, studies that assess the effect of a specific intervention targeted at strengthening life skills or teacher quality, where life skills are measured by a behavioral proxy, find significant, positive treatment effects [2], [7], [8]. 
Figure 2. Summary of studies that evaluate the impact of education or high school interventions on life skills

\begin{tabular}{|c|c|c|c|}
\hline $\begin{array}{l}\text { Country } \\
\text { [Study] }\end{array}$ & Data, year & Treatment & Method \\
\hline $\begin{array}{l}\text { Australia } \\
\text { [author's } \\
\text { own] }\end{array}$ & HILDA, 2005-2013 & $\begin{array}{l}\text { Staying in high school one } \\
\text { extra year }\end{array}$ & OLS \\
\hline Australia [4] & HILDA, 2005-2013 & $\begin{array}{l}\text { University education/degree } \\
\text { vs no degree }\end{array}$ & $\begin{array}{l}\text { First-difference model and } \\
\text { matching }\end{array}$ \\
\hline England [10] & $\begin{array}{l}\text { Administrative } \\
\text { English school data of } \\
\text { participating schools and } \\
\text { students }\end{array}$ & $\begin{array}{l}\text { Participation in XL Club program } \\
\text { which targets underachieving } \\
\text { students' confidence, self- } \\
\text { esteem, and motivation in } \\
\text { secondary schools }\end{array}$ & $\begin{array}{l}\text { Matching on observables } \\
\text { and unobservables }\end{array}$ \\
\hline Germany [5] & GSOEP, 2005-2009 & $\begin{array}{l}\text { Exogenous variation in learning } \\
\text { intensity in university-track } \\
\text { school }\end{array}$ & $\begin{array}{l}\text { Comparison between } \\
\text { treated and non-treated } \\
\text { graduation cohorts }\end{array}$ \\
\hline Germany [6] & $\begin{array}{l}\text { University track high } \\
\text { school student surveys } \\
\text { Saxony-Anhalt, } 2009\end{array}$ & $\begin{array}{l}\text { Exogenous variation in learning } \\
\text { intensity in university-track } \\
\text { secondary school }\end{array}$ & $\begin{array}{l}\text { Comparison between } \\
\text { treated and non-treated } \\
\text { graduation cohorts }\end{array}$ \\
\hline US [1] & $\begin{array}{l}\text { Administrative and } \\
\text { survey data from a large } \\
\text { sample of 8th grade } \\
\text { students in Boston, } \\
2010-2011\end{array}$ & $\begin{array}{l}\text { Participation in oversubscribed } \\
\text { charter schools who teach } \\
\text { "Work hard, be nice" }\end{array}$ & $\begin{array}{l}\text { 2SLS-IV whether student } \\
\text { won access to charter } \\
\text { school via lottery }\end{array}$ \\
\hline US [2] & $\begin{array}{l}\text { Administrative data from } \\
\text { Chicago Public Schools, } \\
\text { 2003-2013 }\end{array}$ & $\begin{array}{l}\text { Participation in OneGoal, a } \\
\text { program in which selected } \\
\text { teachers coaches high school } \\
\text { students to access college and } \\
\text { to train life skills }\end{array}$ & $\begin{array}{l}\text { Matching on observables } \\
\text { and unobservables }\end{array}$ \\
\hline US [3] & NLSY79 & $\begin{array}{l}13+\text { years of schooling vs }<12 \\
\text { years of schooling for men }\end{array}$ & $\begin{array}{l}\text { Simultaneous equation } \\
\text { modeling }\end{array}$ \\
\hline US [7] & NELS, 1988 & 8th grade class size & $\begin{array}{l}\text { Within-student, within- } \\
\text { teacher comparisons } \\
\text { across academic subjects }\end{array}$ \\
\hline US [8] & $\begin{array}{l}\text { Administrative data, } \\
\text { 9th grade public } \\
\text { school North Carolina, } \\
\text { 2005-2011 }\end{array}$ & $\begin{array}{l}\text { High teacher quality relative } \\
\text { to low teacher quality }\end{array}$ & $\begin{array}{l}\text { Matching based on past } \\
\text { performance }\end{array}$ \\
\hline US [9] & $\begin{array}{l}\text { Survey and } \\
\text { administrative data of } \\
\text { 11th and 12th grade } \\
\text { students Harlem School } \\
\text { Zone, 2005-2006 }\end{array}$ & $\begin{array}{l}\text { Participation in Promise } \\
\text { Academy ("No Excuses"), } \\
\text { extended school day/year, after- } \\
\text { school tutoring, teaching of the } \\
\text { importance of hard work, grit, } \\
\text { and persistence }\end{array}$ & $\begin{array}{l}\text { 2SLS-IV whether student } \\
\text { won access to charter } \\
\text { school via lottery }\end{array}$ \\
\hline US [11] & $\begin{array}{l}\text { Administrative Chicago } \\
\text { Public School data, } \\
\text { electronic arrest records } \\
\text { and student surveys }\end{array}$ & $\begin{array}{l}\text { "Becoming a Man" } \\
\text { intervention, regular exposure } \\
\text { to pro-social adults, after- } \\
\text { school programming, and } \\
\text { cognitive behavioral therapy }\end{array}$ & $\begin{array}{l}\text { Random allocation into } \\
\text { treatment group }\end{array}$ \\
\hline
\end{tabular}

Source: For full source details see: http://wol.iza.org/articles/does-education-strengthen-the-life-skills-of-adolescents 
Negative effects are also found in two high-quality studies that assess the effect of participation in US charter schools, which promote a strong work ethic and stress achievement, conscientiousness, grit, self-control, and self-esteem [1], [9]. Both studies find a negative effect of school participation on grit, raising the question of whether some education programs may have harmful effects, which is discussed in detail later on.

Only one study uses a randomized control trails (RCT) design-the gold standard to identify causal effects-to evaluate a high school intervention that used cognitive behavioral therapy (CBT) to improve life skills of disadvantaged adolescents [11]. The authors find tentative evidence that CBT improves adolescents' emotional health and grit. CBT is not commonly used in high schools, so this study proposes a novel approach to reverse unsustainable life skills of at-risk students in a potentially cost-effective way.

\section{Size of the treatment effects and methods}

\section{Effect of education on self-assessed life skill measures}

The sign and significance of the impact of education or education programs on life skill development does not inform whether the effects sizes are economically meaningful. This section will therefore report, where available, the effect sizes in terms of standard deviation (std. dev.) change. Calculations of associations between years of education and life skills based on HILDA data yield relatively small relationships for conscientiousness $(0.04$ std. dev.), emotional stability (0.03 std. dev.), and internal locus of control (0.07 std. dev.), and slighter larger ones for openness to experience $(0.12 \mathrm{std}$. dev.), risk tolerance $(0.11$ std. dev.), and future orientation (0.10 std. dev.).

One study, which models education decisions and two specific life skills simultaneously to estimate the causal impact of education with data from the National Longitudinal Survey of Youth (NLSY79) [3], finds that men who completed 13 or more years of schooling score over 0.35 std. dev. and $0.70 \mathrm{std}$. dev. higher on internal locus of control and self-esteem, respectively, than men who completed less than 12 years of schooling. The magnitudes of the impact of higher levels of education are by far the largest across all reviewed studies. The reason is that the unit of the treatment effect reflects college education relative to high school dropout; thus, treatment implies here a very large dose.

Another study assesses the causal impact of university education on life skill developmentmeasured by the big five personality traits-of adolescents in Australia [4]. The authors follow several birth cohorts from adolescence into young adulthood and track their skills before, during, and after they complete university. Using first-difference and matching methods, and controlling for a large set of potentially confounding variables, the study finds that university education generally boosts extraversion significantly by $0.24 \mathrm{std}$. dev. and $0.40 \mathrm{std}$. dev., respectively. These results are independent of the university at which students study. The study also finds that students from disadvantaged backgrounds improve their agreeableness scores-a good proxy for altruistic and prosocial behaviorthrough university education by around $0.20 \mathrm{std}$. dev., while students from advantaged backgrounds decrease their agreeableness scores by around $0.25 \mathrm{std}$. dev. The authors do not find robust effects of university education on conscientiousness and openness to experience, which is a surprising result, because university training and campus life usually offer an intensive new learning environment. 
Two recent studies from Germany explore how life skills are affected by a recent reform that reduced the duration of high school from nine to eight years, while keeping the same curriculum, for adolescents on college track [5], [6]. Both studies use the same outcome measures (big five personality traits, internal locus of control), but one uses data from the German Socio-Economic Panel (GSOEP) (a nationally-representative survey) [6], while the other uses primary survey data from Saxony-Anhalt collected on high school graduates two years after the implementation of the reform [5]. Both studies sought to identify the potential cost of a reform that increased the learning intensity and potential stress levels of affected students. The two studies arrive at quite different conclusions.

The study from Saxony-Anhalt [6] shows that the reform significantly reduced male students' neuroticism by almost 0.19 std. dev., internal locus of control by 0.10 std. dev., self-control perceptions by $0.10 \mathrm{std}$. dev., although it did increase openness to experience by $0.09 \mathrm{std}$. dev. The reform also significantly reduced female students' conscientiousness by almost $0.10 \mathrm{std}$. dev., while it increased their extraversion by almost $0.10 \mathrm{std}$. dev. The authors interpret these effects as small to moderate, concluding that the reform was neither particularly beneficial nor harmful for German high school students.

In contrast, the study based on nationally representative German data [5] finds that shortening the high school track caused German students to be more extroverted by 0.23 std. dev. and more neurotic by $0.24 \mathrm{std}$. dev. The study's findings on extraversion are in line with the findings in the Saxony-Anhalt study, but the positive effects on neuroticism contradict those findings, which show significant negative effects on neuroticism in a combined sample of men and women (-0.13 std. dev.) [6]. The authors of [5] conclude that the reform increased pressure on students, which could be seen as harmful.

\section{Effect of life skill strengthening programs on self-assessed life skill measures}

Several studies evaluate the longer-term effects of school programs that directly target life skill development of adolescents [1], [9], [11]. All three are able to provide credible causal estimates of the effect of the intervention because they either use data from an RCT [11] or a lottery that randomly allocates individuals into school program participation [1], [9].

One of these studies compares the achievement of students accepted by a lottery to the Promise Academy charter school in Harlem (New York, US) to the students who did not receive a spot through the lottery [9]. Charter schools differ from other public schools because of their explicit focus on life skill development. They use extended school days, recruitment of high-quality teachers, data-driven monitoring of students' progress, smallgroup tutoring based on past performance, and cultivate a culture of achievement. Students in the treatment group entered the Promise Academy in grade six. Survey and administrative data on outcomes were collected six years later when the students completed grade 12. Lottery winners outscore lottery losers substantially and significantly on a range of academic outcomes. They are also less likely to experience teen pregnancy, use illegal drugs, or be involved in criminal activity. However, despite the positive impact on academic and non-academic outcomes, the study finds no or even negative effects on life skills. For instance, lottery winners score $0.12 \mathrm{std}$. dev. lower on the self-esteem scale and 0.25 std. dev. lower on the grit scale. There is no effect on internal locus of control (0.05 std. dev.).

Another study uses a similar strategy using data from Boston-based (Massachusetts, US) charter schools [1]. The authors compare the outcomes of lottery winners and lottery 
losers in two high-achieving charter schools that pursue a radical "No Excuses" policy, characterized by high expectations and support for students. Although the lottery winners significantly out-perform lottery losers on test scores, they score significantly lower on indices of grit (-0.12 std. dev.), conscientiousness (-0.16 std. dev.), and self-control (-0.21 std. dev.), similar to the findings reported in the Harlem study.

The study on Boston charter schools [1] discusses explicitly the reasons why negative effects on life skill development might be found in both charter schools [1], [9], reasons that may also explain the insignificant or negative effects found for university education or education reforms [4], [5], [6]. The authors of the Boston study suggest that reference bias, the "tendency for survey responses to be influenced by the social context," may explain the negative treatment effects [1]. Accordingly, students who attend the academically and behaviorally demanding charter schools may "redefine upward their notion of what it means to demonstrate conscientiousness, self-control, and grit-and thus rate themselves more critically" [1].

This finding implies that using self-reported measures of life skills to assess the effectiveness of a school to teach life skills may lead to erroneous conclusions. Students who are exposed to higher standards of life skills may downgrade their self-perceived abilities, even if they have improved them on objective terms, and this would mask teachers' success in teaching such skills.

Finally, one study evaluates the effectiveness of "Becoming a Man," a high school intervention that targets disadvantaged males in grades 7 to 10 who live in high-crime Chicago neighborhoods [11]. An important component of the intervention was CBT designed "to get youth to 'think about thinking' (promote meta-cognition): that is, to recognize situations in which automatic, intuitive decision-making may lead to trouble and to recognize (and correct) biased beliefs or interpretations of their experiences" [11]. The average program participant received 13 sessions.

The program significantly reduced violent crime arrests by $44 \%$ and improved gradepoint averages by 0.19 std. dev. during the follow-up year. Additional primary survey data collected on a reduced sample of participants provides tentative evidence that the intervention was also successful in boosting life skills. Gains were recorded in self-assessed measures of grit and emotional health in the magnitude of $0.13 \mathrm{std}$. dev., although the researchers have less certainty that these estimates are different from zero because of very wide confidence intervals.

This study is significant because it provides a cost-benefit analysis of the intervention against which other interventions can be benchmarked. Overall, the intervention cost was $\$ 1,100$ per participant. Monetized benefits were between 2 and 30 times the intervention costs.

\section{Effects of education programs on behavioral proxies of life skills}

Sometimes life skill measures are not available in the data that researchers use to evaluate the impact of a program. Therefore, some studies use behavioral proxies of life skills, such as absences, school engagement, or on-time graduation, to evaluate the impact of schooling or education programs [2], [7], [8], [10]. Using behavioral proxies is justified on the grounds that in-class behaviors reveal difficult-to-measure behavioral styles.

One study assesses the impact of the XL Club program, which targeted underachieving 14-year-olds in English secondary schools [10]. The program aimed to help at-risk 
students to complete compulsory education and improve their age-16 test score results by strengthening life skills. Unfortunately, participation in the program was not random because teachers recommended individual students to the program based on prior academic achievements. Therefore, it was the worst-performing students who benefited from the program that were then compared against the better-performing children. Life skills were not directly measured either, so the authors use authorized and unauthorized absence rates as proxies for life skills.

The authors found that students in the XL Club program increased the probability of excused and unexcused absences by 2 and 1.4 percentage points, respectively, indicating that the program harmed participating students. Yet the authors claim that this increase in absences may be due to the selection effect of the poorest students into program participation. When controlling for this selection through a simulation exercise, the authors find indeed a negative effect of the program on absence rates, reducing absences by more than 10 percentage points. The authors interpret this as evidence that the program was effective in improving life skills.

Another US study evaluates the effect of teacher quality on student outcomes and life skill development using data on all ninth grade public school students in North Carolina, US, from 2005 to 2011 [8]. In this study, life skills are measured as a weighted average of absences, suspensions, course grades, and on-time grade progression. The study finds that students who have a mathematics and English teacher in the 85th percentile of the test-score distribution (a proxy for teacher quality) relative to students with teachers in the bottom 15th percentile, report significantly higher values of life skills, in the range of $0.12 \mathrm{std}$. dev. and $0.15 \mathrm{std}$. dev.

Finally, yet another US study estimates the effects of eighth grade class sizes on student effort using teacher assessment (i.e. attention or disruption) [7]. The students were asked to self-assess their effort in class at the first follow up two years later. The analysis uses observational data from the National Education Longitudinal Study (1988). To identify the causal effect of class size on effort in class, the authors compare the performance of the same student taught by the same teacher in two different academic subjects. They find that students engage significantly more in smaller classes. A one-standard deviation decrease in class size-moving from 24 to 18 students-leads to an immediate increase in academic engagement by 0.05 to 0.08 std. dev., and a long-term increase in trying hard in class by $0.03 \mathrm{std}$. dev. One advantage of this study is that it produced an internal rate of return calculation for reducing class size from 24 to 18 students, where estimates range between $3.6 \%$ and $5.6 \%$, depending on assumptions made about productivity growth.

\section{Are the effects of education large or small?}

Whether the treatment effects are large or small is relative. With the exception of two studies that find treatment effects between $0.40 \mathrm{std}$. dev. (on extraversion) and $0.70 \mathrm{std}$. $\operatorname{dev}$ (on self-esteem) [3], [4], all treatment effects are bound between - 0.25 std. dev. and 0.25 std. dev. To gain a better understanding of whether these treatment effects are economically meaningful, it is helpful to benchmark them against estimates on the observed malleability of life skills in response to common life events or the treatment effects of early-childhood interventions on life skills. 
Two studies report the magnitudes of the effects of standard life events such as health shocks or unemployment experiences on changes in the big five personality traits and internal locus of control over a four-year window, which is comparable in length to the duration of high school or university education [12], [13]. On average, the authors find that life skills are relatively stable and the majority of life events in the health, labor market, and family domain have little impact on life skill dynamics in adulthood. The largest effects are found for a small group of women who experienced a series of traumatic life events (lost job, death of spouse, health problems), which are exceptional and rare cases in the data, within a four-year window. For these women, internal locus of control significantly declined by 0.30 std. dev. [12]. Equally, a small group of individuals who experienced repeated financial shocks (i.e. worsening financial problems, job loss) reduced their conscientiousness significantly by $0.25 \mathrm{std}$. dev. [13].

Another legitimate benchmark is the treatment effect of early childhood interventions such as the Ypsilanti (Michigan, US) High Scope/Perry Preschool Program (PPP) on children's life skill development. Random participation in the PPP significantly increased academic motivation and decreased problem behaviors in girls aged seven to nine. Girls who participated in the program scored $0.40 \mathrm{std}$. dev. higher on academic motivation and $0.50 \mathrm{std}$. dev. lower on externalizing behavior.

The changes in adolescent life skills-ranging between -0.25 std. dev. and +0.25 std. dev.-due to education or high school interventions are close to the average life skill losses reported for heavily traumatized adult women (in a representative Australian sample). They are also about $50 \%$ in size compared to the effects in girls in the PPP. The findings in the PPP, one of the most powerful early childhood interventions targeting very disadvantaged children, could be considered as an upper bound of what is possible. Therefore, the treatment effects of education and education programs on adolescent life skill development are by no means negligible.

\section{LIMITATION AND GAPS}

The evidence on the effectiveness of secondary or tertiary education in boosting life skills is still too scattered for concrete policy recommendations. Although a small portfolio of studies exists, it is unknown which life skills are most responsive to education initiatives. Unlike cognitive skills, assessment of life skills is based on self-reporting, which is not useful in assessing teachers' effectiveness in strengthening student development. Too little is known about the degree to which reference bias in self-reported life skills could obscure the treatment effects. Moreover, too little is known about the extent to which behavioral proxies could reliably measure life skills, as almost none of the reviewed studies has validated their relationship with measures of life skills (an exception is [1]).

\section{SUMMARY AND POLICY ADVICE}

The educational landscape is changing and, in this context, life skills are increasingly mentioned as relevant skills that children and adolescents should learn. The small portfolio of studies suggests that life skills of adolescents can be strengthened through education and education programs. Yet, no consensus emerges from these studies about which life skills are most important and desirable. Studies typically measure life skills with whatever proxy is available in the data. Some are based on standard inventories to 
measure personality traits or preferences, while others capture noncognitive facets of skills with broad behavioral proxies derived from administrative data. Yet, all of them use such measures with the acknowledgment that academic achievement is too narrow a concept to assess developmental outcomes of adolescents.

Based on the evidence, governments interested in changing curricula in favor of introducing life skill development into their schools should consult local stakeholders to identify the most preferable skill portfolio for students. The procedures followed by Canada's OttawaCarleton School District Board, which has introduced the teaching of five life skills into standard curricula, offer a useful example for other districts or countries to follow. Yet, the Ottawa-Carleton School District Board has not yet found ways to assess life skill developments other than via student self-assessments.

The findings from the literature that students are likely to adjust their benchmark against which they compare themselves as they navigate through the education system suggests that teacher assessments should be prioritized over student self-assessments to gauge the progress of life skill developments. However, even teacher assessments require a knowledge base of validated and observable behaviors that can be used as proxies for measuring life skills in adolescence.

One impressive example is the innovative work on the Early Development Indices from both Australia and Canada that use teacher assessments to monitor the skill development of their nations' population aged five. Similar assessment tools could be developed for monitoring the skill development of young adolescents.

The findings from the small portfolio of studies also emphasize that very little is known about the cost-effectiveness of specific education programs to strengthen life skills. Only two studies produced a rate of return estimate-one for class size reductions and one for the use of CBT-against which alternative programs could be compared. As such, more pilot projects are needed to evaluate the (cost-)effectiveness of alternative methods to teach life skills, preferably in the form of RCTs.

\section{Acknowledgments}

The author thanks an anonymous referee and the IZA World of Labor editors for many helpful suggestions on earlier drafts. Previous work of the author contains a larger number of background references for the material presented here and has been used intensively in all major parts of this article (http://www.stefanie-schurer.com/publications). Financial support from the Australian Research Council for financial support through a Discovery Early Career Fellowship (DE140100463) and Centre of Excellence for Children and Families over the Life Course (project number CE140100027) is gratefully acknowledged. The author would like to thank Sonja Kassenboehmer, Martin West, and Tim Kautz for helpful comments.

\section{Competing interests}

The IZA World of Labor project is committed to the IZA Guiding Principles of Research Integrity. The author declares to have observed these principles. 


\section{REFERENCES}

\section{Further reading}

Almlund, M., A. Lee Duckworth, J. J. Heckman, and T. Kautz. "Personality psychology and economics." In: Eric, S. M., A. Hanushek, and L. Woessmann (eds). Handbook of the Economics of Education, Volume 4. Amsterdam: North-Holland, 2011; pp. 1-181.

Casey, B. J., R. M. Jones, and T. A. Hare. "The adolescent brain." Annals of the New York Academy of Sciences 1124 (2008): 111-126.

\section{Key references}

[1] West, M. R., M. A. Kraft, A. S. Finn, R. E. Martin, A. L. Duckworth, C. F. O. Gabrieli, and J. D. E. Gabrieli. "Promise and paradox: Measuring students' non-cognitive skills and the impact of schooling." Educational Evaluation and Policy Analysis 38:1 (2016): 148-170.

[2] Kautz, T., J. J. Heckman, R. Diris, B. ter Weel, and L. Borghans. Fostering and Measuring SkillsImproving Cognitive and Non-cognitive Skills to Promote Lifetime Success. OECD Education Working Papers No. 110, 2015.

[3] Heckman, J. J., J. Stixrud, and S. Urzua. "The effects of cognitive and noncognitive abilities on labor market outcomes and social behavior." Journal of Labor Economics 24:3 (2006): 411-482.

[4] Schurer, S., S. Kassenboehmer, and F. Leung. Do Universities Shape their Students' Personality? IZA Discussion Paper No. 8873, 2015.

[5] Thiel, H., S. L. Thomsen, and B. Büttner. "Variation of learning intensity in late adolescence and the effect on personality traits." Journal of the Royal Statistical Society Series A 177:4 (2014): 861-892.

[6] Dahmann, S., and S. Anger. The Impact of Education on Personality - Evidence from a German High School Reform. CINCH Working Paper Series No. 1505, 2015.

[7] Dee, T. S., and M. West. "The non-cognitive returns to class size." Educational Evaluation and Policy Analysis 33:1 (2011): 23-46.

[8] Jackson, C. K. Non-cognitive Ability, Test Scores, and Teacher Quality: Evidence from 9th Grade Teachers in North Carolina. NBER Working Paper No. 18624, 2012.

[9] Dobbie, W., and R. G. Fryer. "The medium-term impacts of high-achieving charter schools." Journal of Political Economy 123:5 (2015): 985-1037.

[10] Holmlund, H., and O. Silva. "Targeting non-cognitive skills to improve cognitive outcomes: Evidence from a remedial education intervention." Journal of Human Capital 8:2 (2011): 126-160.

[11] Heller, S. B., H. Pollack, R. Ander, and J. Ludwig. Preventing Youth Violence and Dropout: A Randomized Field Experiment. NBER Working Paper No. 19104, 2013.

[12] Cobb-Clark, D., and S. Schurer. "Two economists' musings on the stability of locus of control." The Economic Journal 123:570 (2013): F358-F400.

[13] Cobb-Clark, D., and S. Schurer. "The stability of the Big-Five personality traits." Economics Letters 115:1 (2012): 11-15.

\section{Online extras}

The full reference list for this article is available from:

http://wol.iza.org/articles/does-education-strengthen-the-life-skills-of-adolescents

View the evidence map for this article:

http://wol.iza.org/articles/does-education-strengthen-the-life-skills-of-adolescents/map 